STUDIA EDUKACYJNE NR 50/2018

\author{
KONRAD KULIKOWSKI \\ Uniwersytet Jagielloński
}

\title{
IDEA UNIWERSYTETU KSZTAŁCĄCEGO LUDZI ZAANGAŻOWANYCH W PRACĘ
}

\begin{abstract}
AвSTRACT. Kulikowski Konrad, Idea uniwersytetu kształcacego ludzi zaangażowanych w pracę [An Idea of a University Teaching Work-Engaged People]. Studia Edukacyjne nr 50, 2018, Poznań 2018, pp. 387-397. Adam Mickiewicz University Press. ISSN 1233-6688. DOI: 10.14746/se.2018.50.25

The first part of this article introduces the work engagement concept in a framework of the Job Demands-Resources Theory and discusses a relation between work engagement and job crafting. Next, the author presents the hypothesis that university education can form engaged employees by enhancing students' self-efficacy beliefs about their ability to effectively crafting their future job environments. On the basis of the Social Learning Theory the author proposed three possible methods on how the university community could promote job crafting behaviors among students. These methods are: trainings and persuasions, modeling, or observation of how university top researchers work, and allowing students to experience success in changing different aspects of the university environment.
\end{abstract}

Key words: university, employee engagement, Job Demands-Resources theory, job crafting, education

Uniwersytet nie jest szkołą zawodową, lecz jednym z jego celów stanowi przygotowanie do pracy zawodowej i praktycznego stosowania wiedzy naukowej. Nieliczni studenci pozostają w murach Alma Mater, by odkrywać prawdy i prawdopodobieństwa naukowe. Większość wyrusza w świat, by wykonywać wyuczony na studiach fach. Zatem, warto zatroszczyć się o zawodową przyszłość studentów, a przejawem tej troski może być zaoferowanie studentom czegoś więcej niż dostępu do aktualnej i użytecznej wiedzy. Uniwersytet ze względu na swoją specyfikę może oferować studentom nie tylko zajęcia ściśle związane z kierunkiem ich studiów, ale także zajęcia ogólnouniwersyteckie, kształtujące postawy i przekonania ułatwiające odniesienie sukcesu na rynku pracy. Głównym celem prezentowanej pracy jest przedstawienie idei, że uniwersytety wdrażając określone programy zajęć, mogłyby kształcić ludzi zaangażowanych w pracę. Można tego dokonać poprzez budowanie w studentach przekonania o własnej skuteczności (ang. self-effica- 
$c y)^{1} \mathrm{w}$ zakresie aktywnego zmieniania środowiska pracy. Badania naukowe dowodzą ${ }^{2}$ że istotnym czynnikiem prowadzącym do zaangażowania $\mathrm{w}$ pracę jest samodzielna aktywność pracownika (ang. job crafing), prowadząca do kształtowania środowiska pracy tak, by było bardziej przyjazne i korzystne dla pracownika ${ }^{3}$. Zatem, jeśli uniwersytety kształciłyby w studentach postawę aktywności i budowały przekonanie o potrzebie samodzielnego zmieniania środowiska zawodowego, to mogłyby tym samym zwiększać poziom zaangażowania studentów w ich przyszłej pracy.

\section{Czym jest zaangażowanie $w$ pracę?}

Zaangażowanie $\mathrm{w}$ pracę jest terminem $\mathrm{z}$ dziedziny psychologii pozytywnej, a więc tej dziedziny psychologii, która zamiast koncentrować się na deficytach, analizuje raczej ludzkie zalety i mocne strony ${ }^{4}$. Zaangażowanie w pracę rozumiane może być na wiele sposobów ${ }^{5}$; dla zachowania jasności na potrzeby niniejszej pracy zaangażowanie $\mathrm{w}$ pracę zdefiniowano za W. Schaufelim jako pozytywny stan umysłu (fulfilling state of mind), na który składa się wigor, oddanie się pracy i zaabsorbowanie nią ${ }^{6}$. Wigor to wysoki poziom energii podczas wykonywania pracy i zapał do niej. Oddanie się pracy to wiara w jej celowość, przekonanie, że to co się robi ma sens i znaczenie. Zaabsorbowanie pracą to poznawcze pogrążenie się $\mathrm{w}$ pracy podczas jej wykonywania, powiązane z uczuciem zadowolenia podczas pracy, jak i poczu-

\footnotetext{
${ }^{1}$ A. Bandura, Self-efficacy: toward a unifying theory of behavioral change, Psychology Review, 1977, 84, s. 191-215; tenże, Teoria społecznego uczenia się, Warszawa 2007.

${ }^{2}$ M. Tims, A.B. Bakker, D. Derks, The Impact of Job Crafting on Job Demands, Job Resources, and Well-Being, Journal of Occupational Health Psychology, 2013, 18(2), s. 230-240; C. Lu i in., Does work engagement increase person-job fit? The role of job crafting and job insecurity, Journal of Vocational Behavior, 2014, 84, s. 142-152; A. Sakuraya i in., Effects of a job crafting intervention program on work engagement among Japanese employees: a pretest-posttest study, BMC Psychology, 2016, 4(1), http:// doi.org/10.1186/s40359-016-0157-9.

3 E. Demerouti, Design your own job through job crafting, European Psychologist, 2014, 19(4), s. 237-243.

${ }^{4}$ K.M. Sheldon, L. King, Why positive psychology is necessary, American Psychologist, 2001, 56(3), s. 216-217.

${ }^{5}$ W.A. Kahn, Psychological condition of Personal Engagement and Disengagement at Work, Academy of Management Journal, 1990, 33(4), s. 692-724; tenże, To Be Fully There: Psychological Presence at Work, Human Relations, 1992, 45(4), s. 321-349; C. Maslach, M.P. Leiter, Early Predictors of Job Burnout and Engagement, Journal of Applied Psychology, 2008, 93(3), s. 498-512; W.H. Macey, B. Schneider, The Meaning of Employee Engagement, Industrial and Organizational Psychology, 2008, 1, s. 3-30.

${ }^{6}$ W.B. Schaufeli, A.B. Bakker, M. Salanova, The measurement of work engagement with a short questionnaire: A cross-national study, Educational and Psychological Measurement, 2006, 66, s. 701-716.
} 
ciem nienaturalnie szybkiego upływu czasu podczas wykonywania pracy ${ }^{7}$. Zaangażowanie nie jest jedynie przeciwieństwem wypalenia zawodowego, ale innym jakościowo wymiarem funkcjonowania zawodowego człowieka ${ }^{8}$.

Zaangażowanie $\mathrm{w}$ pracę przynosi korzyści zarówno pracownikom, jak też ich pracodawcom. Pracownicy zaangażowani cechują się lepszym zdrowiem $^{9}$, przejawiają wyższy poziom zadowolenia z pracy i całości życia ${ }^{10}$. Co więcej, zaangażowani oddziałują także na efektywność funkcjonowania organizacji, poziom zysków firm i satysfakcję klientów ${ }^{11}$.

Przytaczana tu koncepcja zaangażowania Schaufeliego umiejscawia je w ramach szerszego modelu teoretycznego, teorii wymagań i zasobów pracy - Job Demands Resources Theory (JD-R) ${ }^{12}$. Zaangażowanie w pracę (work engagement) jest tutaj wynikiem interakcji wymagań, jakie stawia praca oraz zasobów pracy i zasobów osobistych. Wymagania to wszystkie te czynniki, które pracę utrudniają, zasoby z kolei to czynniki związane z osobą pracownika i charakterystykami pracy, które pomagają w realizowaniu zawodowych obowiązków i redukują napięcie generowane przez wymagania ${ }^{13}$. Istotne dla prezentowanej $\mathrm{w}$ tej pracy idei jest empirycznie potwierdzone założenie teorii JD-R stanowiące, iż pracownicy mogą samodzielnie oddziaływać na poziom swojego zaangażowania poprzez aktywne zmienianie środowiska pracy (job crafting) w taki sposób, by generowało zasoby i obniżało wymagania, tworząc warunki do roz-

7 W.B. Schaufeli, A.B. Bakker, Defining and measuring work engagement: Bringing clarity to the concept, [w:] Work engagement: a handbook of essential theory and research, red. A.B. Bakker, M.P. Leiter, New York 2010, s. 10-24.

8 W.B. Schaufeli, T.W. Taris, W. van Rhenen, Workaholism, Burnout, and Work Engagement: Three of a Kind or Three Different Kinds of Employee Well-being? Applied Psychology, 2008, 57(2), s. 173-203.

${ }^{9}$ A. Airila i in., Are job and personal resources associated with work ability 10 years later? The mediating role of work engagement, Work \& Stress, 2014, 28(1), s. 87-105; O.M. Karatepe i in., Does work engagement mediate the effects of challenge stressors on job outcomes? Evidence from the hotel industry, International Journal of Hospitality Management, 2014, 36, s. 14-22; A. Shimazu i in., Workaholism vs. Work Engagement: the Two Different Predictors of Future Well-being and Performance, International Journal of Behavioral Medicine, 2015, 22(1), s. 18-23.

10 J.J. Hakanen, W.B. Schaufeli, Do burnout and work engagement predict depressive symptoms and life satisfaction? A three-wave seven-year prospective study, Journal of Affective Disorders, 2012, $141(2-3)$, s. $415-24$.

11 J.K. Harter i in., Causal Impact of Employee Work Perceptions on the Bottom Line of Organizations, Perspectives on Psychological Science, 2010, 5(4), s. 378-389; D. Xanthopoulou i in., Work engagement and financial returns: A diary study on the role of job and personal resources, Journal of Occupational and Organizational Psychology, 2009, 82(1), s. 183-200.

12 A.B. Bakker, E. Demerouti, The Job Demands-Resources Theory, [w:] Work and Wellbeing: A Complete Reference Guide, Vol. III, red. P.Y. Chen, C.L. Cooper, West Sussex 2014, s. 37-65.

13 A.B. Bakker, A.I. Sanz-Vergel, Weekly work engagement and flourishing: The role of hindrance and challenge job demands, Journal of Vocational Behavior, 2013, 83(3), s. 397-409. 
woju zaangażowania ${ }^{14} . \mathrm{W}$ takim ujęciu, zaangażowanie $\mathrm{w}$ pracę to nie tylko wynik działania niezależnych od jednostki czynników, ale także konsekwencja jej aktywności - świadomych działań w środowisku pracy.

\section{Czym jest aktywne zmienianie środowiska pracy?}

Idea aktywnego zmieniania środowiska pracy przez samych pracowników (job crafting) wywodzi się z nurtu tak zwanej reorganizacji pracy (ang. job-redesign), a więc ciągłego zmieniania przez kierownictwo właściwości i sposobu organizacji pracy w celu jak najlepszego dostosowania jej do fizycznych, jak i psychologicznych potrzeb pracowników ${ }^{15}$. Niestety, okazuje się, iż zmiany planowane odgórnie przez menedżerów o pozytywnych oddziaływaniach na pracowników nie zawsze prowadzą do oczekiwanych rezultató $w^{16}$. Stąd pojawiła się potrzeba uzupełnienia zmian odgórnych planowanych przez kadrę zarządzającą zmianami oddolnymi podejmowanymi z inicjatywny samych pracowników. Przykładem takich właśnie zmian oddolnych jest aktywne zmienianie środowiska pracy (job crafting), które może być definiowane jako fizyczne i poznawcze zmiany wprowadzone przez jednostkę $\mathrm{w}$ jej zadaniach lub relacjach $\mathrm{z}$ innymi pracownika$\mathrm{mi}, \mathrm{w}$ celu usprawnienia wykonywania pracy ${ }^{17}$. Fizyczne zmiany dotyczą zmian $\mathrm{w}$ formie, zakresie lub liczbie zawodowych zadań, podczas gdy poznawcze zmiany odnoszą się do zmiany tego, jak pracownik postrzega swoją pracę ${ }^{18}$. Petrou i współpracownicy $(2012)^{19}$ sugerują, że ludzie modyfikują swoją pracę, aby stworzyć bardziej odpowiadające im warunki pracy i pozostać zdrowym oraz zaangażowanym. Również inni badacze ${ }^{20}$ zwracają uwagę, iż pracownicy mogą zmieniać swoje środowisko pracy tak, by pozostać zaangażowanymi w obliczu zachodzących zmian. Pracownicy mogą

${ }^{14}$ M. Tims, A.B. Bakker, D. Derks, Development and validation of the job crafting scale, Journal of Vocational Behavior, 2012, 80(1), s. 173-186.

15 A.M. Grant, S.K. Parker, Redesigning work design theories: The rise of relational and proactive perspectives, Academy of Management Annals, 2009, 3, s. 273-331.

${ }^{16}$ S.K. Parker, T.D. Wall, J. Cordery, Future work design research and practice: Towards an elaborated model of work design, Journal of Occupational and Organizational Psychology, 2001, 74, s. 413-440.

${ }^{17}$ E. Demerouti, Design your own job, s. 237-243.

18 A. Wrzesniewski, J.E. Dutton, Crafting a job: Revisioning employees as active crafters of their work, Academy of Management Review, 2001, 26, s. 179-201.

${ }_{19}$ P. Petrou i in., Crafting a job on a daily basis: contextual antecedents and the effect of work engagement, Journal of Organizational Behavior, 2012, 33, s. 1120-1141.

${ }^{20}$ A.B. Bakker, S.L. Albrecht, M.P. Leiter, Work engagement: Further reflections on the state of play, European Journal of Work and Organizational Psychology, 2011, 20(1), s. 74-88; M. Tims, A.B. Bakker, D. Derks, The Impact of Job Crafting on Job Demands, s. 230-240. 
aktywnie zmieniać swoją pracę, na przykład poprzez zwiększanie wymagań pracy wtedy, gdy są znudzeni (np. stawianie sobie trudnych celów) lub poszukiwanie zasobów pracy, gdy wymagania są zbyt wysokie (np. zabieganie o wsparcie bardziej doświadczonych pracowników). Zaangażowani pracownicy aktywnie zmieniają swoje środowisko pracy, dostosowując występujące $\mathrm{w}$ nim wymagania do posiadanych zasobów ${ }^{21}$.

\section{Jak uniwersytety mogą kształcić do zaangażowania w pracę?}

Reasumując wcześniejsze rozważania, można zauważyć, iż po pierwsze - zaangażowanie w pracę jest korzystne zarówno dla pracownika, jak i pracodawcy, dlatego opłaca się dążyć do jego rozwoju. Po drugie - pracownik poprzez aktywne zmienianie środowiska pracy sam może zwiększać poziom swojego zaangażowania. Takie aktywne zmienianie środowiska pracy to redukowanie wymagań oraz świadome budowanie zasobów pracy, ułatwiających realizację zawodowych celów, redukujących wymagania i zmniejszających ponoszone przez pracownika psychofizjologiczne koszty. Wydaje się, iż ze względu na swoją specyfikę uniwersytet może być miejscem, w którym studentom przekazane zostaną przekonania, iż warto być aktywnym i świadomie działać na rzecz poprawy własnej sytuacji zawodowej. Innymi słowy, uniwersytet może kształcić ludzi aktywnych, którzy nie poprzestają na biernym uczestnictwie w życiu zawodowym, ale starają się świadomie kształtować otaczający ich świat, co prowadzi do rozwoju zaangażowania w pracę. Edukacja uniwersytecka może stać się czymś więcej niż tylko przekazywaniem i testowaniem wiedzy, może znaleźć się tu także miejsce na rozwój przekonań i postaw studenta. Aby jednak studenci podejmowali działania ukierunkowane na aktywne zmienianie właściwości swojej przyszłej pracy, muszą podczas edukacji uniwersyteckiej nabyć przekonanie, że mają wystarczające kompetencje, by takie aktywne działania z sukcesem przeprowadzać. Zdaniem twórcy teorii społecznego uczenia się A. Bandury ${ }^{22}$, rozwój przekonań o tym, iż można odnieść sukces w zakresie jakiegoś działania, wytwarza się poprzez trzy zasadnicze źródła informacji: (1) perswazję słowna, (2) obserwowanie sukcesów innych oraz (3) doświadczanie własnych sukcesów ${ }^{23}$. Właśnie

21 C. Lu i in., Does work engagement increase person-job fit? s. 142-152.

22 A. Bandura, Self-efficacy: toward a unifying theory, s. 191-215; tenże, Teoria społecznego uczenia się.

${ }^{23}$ W. Harrison $\mathrm{i}$ in., Testing the self-efficacy-performance linkage of social-cognitive theory, The Journal of Social Psychology, 1997, 137, s. 79-87; A.R. Artino, Academic self-efficacy: from educational theory to instructional practice, Perspectives on Medical Education, 2012, 1, s. 76-85. 
z tych trzech sposobów dostarczania informacji mogłyby korzystać uniwersytety, kształtując w studentach przekonanie o ich skuteczności w zakresie aktywnego zmieniania środowiska przyszłej pracy zawodowej.

\section{Perswazja słowna}

Demerouti i Bakker ${ }^{24}$ (2014) uważają, iż trening w dziedzinie aktywnego zmieniania pracy może odbywać się poprzez promowanie zachowań obywatelskich, podkreślanie znaczenia własnej aktywności dla rozwoju zaangażowania oraz poprzez zachęcanie do zwiększania posiadanych zasobów pracy. Badania empiryczne wskazują, iż tego rodzaju treningi przyczyniają się do zwiększenia poziomu zaangażowania $\mathrm{w}$ pracę ${ }^{25}$. Uniwersytety mogłyby oferować studentom właśnie taki trening aktywności w zakresie zmieniania środowiska pracy - zajęcia, $\mathrm{w}$ ramach których przekazywano by studentom wiedzę o znaczeniu świadomego i aktywnego działania jednostek na rzecz poprawy swojej zawodowej sytuacji. Ponadto, oprócz propagowania idei aktywności i dążenia do zaangażowania, zajęcia nastawione byłyby na przekazywanie wiedzy i kompetencji przydatnych przy inicjowaniu i zarządzaniu zmianami w środowisku pracy. Studenci mieliby możliwość zapoznania się ze strategiami efektywnego rozwiązywania problemów, skutecznymi sposobami komunikacji międzyludzkiej, czy metodyką planowania i wdrażania nowych pomysłów. Efektem takiego treningu powinno być wykształcenie w studentach przekonania, że warto samodzielnie zmieniać środowisko pracy oraz przekonanie, że ma się odpowiednie kompetencje, by to robić. Taki uniwersytecki trening własnej aktywności mógłby wspierać kształtowanie się ludzi aktywnych, którzy nie oczekują, iż to, co im nie odpowiada, samo zmieni się na lepsze, lecz samodzielnie inicjują zmiany w swoim otoczeniu. Wydaje się, iż edukacja uniwersytecka, w odróżnieniu od innych form edukacji, może umożliwiać studentom nie tylko zdobywanie konkretnej wiedzy, ale powinna także wiązać się z ogólnym rozwojem osobowości studenta. Uniwersytet jest unikalnym miejscem umożliwiającym wdrożenie treningów aktywności w zakresie zmieniania środowiska pracy, które kształtowałyby postawy i przekonania studentów prowadzące do zaangażowania w pracę.

${ }^{24}$ E. Demerouti, A. Bakker, Job Crafting, [w:] An Introduction to Contemporary Work Psychology, red. M.C.W. Peeters, J. de Jonge, T.W. Taris, West Sussex 2014, s. 414-433.

${ }^{25}$ E. Demerouti i in., Assessing the effects of a 'personal effectiveness' training on psychological capital, assertiveness and self-awareness using self other agreement, Career Development International, 2011, 16, s. 60-81. 


\section{Sukcesy w wykonywaniu dotychczasowych zadań}

Kolejnym, zdaniem A. Bandury, źródłem informacji, które wpływa na kształtowanie się przekonań o własnej skuteczności jest doświadczanie sukcesów w działaniach. Doświadczenie sukcesu w jakimś działaniu jest bardzo silną informacją zwrotną, iż potrafi się to działanie skutecznie wykonywać.

Uniwersytet mógłby nie tylko uczyć o potrzebie zmieniania środowiska pracy oraz pokazywać studentom możliwe sposoby aktywnego zmieniania środowiska pracy, ale także umożliwić im stosowanie tych działań w praktyce. Uniwersytet jest miejscem, w którym studenci mogą doświadczyć pierwszych sukcesów w aktywnych działaniach ukierunkowanych na zmienianie otaczającego ich świata, a odnoszenie sukcesów w takich działaniach mogłoby z kolei wzmacniać przekonanie, że warto działać i być aktywnym. Aby to osiągnąć, władze uniwersyteckie powinny bardziej niż obecnie zachęcać studentów do aktywnego zmieniania pewnych aspektów rzeczywistości akademickiej poprzez działalność w ramach kół naukowych, samorządów i organizacji uniwersyteckich. Ponadto, aby umożliwić studentom odnoszenie sukcesów w działaniach ukierunkowanych na zmienianie ważnych aspektów otaczającego ich świata, prowadzący zajęcia mogą współdzielić ze studentami „władzę” nad zajęciami dydaktycznymi. Studenci powinni być zachęcani do aktywnego kształtowania programów zajęć tak, aby były zgodne z ich oczekiwaniami. Doświadczając tego, iż ich propozycje i pomysły zmian są uwzględniane i przynoszą realne, korzystne zmiany w przebiegu zajęć, studenci budowaliby w sobie przekonanie, że warto samodzielnie działać na rzecz poprawy swojej sytuacji. Odnoszenie sukcesów w podejmowanych działaniach kształtuje poczucie skuteczności, a uniwersytet mógłby być miejscem, gdzie przy wsparciu społeczności akademickiej studenci mogliby odnosić pierwsze sukcesy w dziedzinie samodzielnego zmieniania otaczającego ich środowiska uniwersyteckiego. Aby tak się jednak stało, społeczność uniwersytecka powinna skupić się na promowaniu i docenianiu aktywności studentów w zakresie działań innych niż tylko uczęszczanie na zajęcia i zdawanie egzaminów. Obecnie aktywność studentów i wysuwane przez nich uwagi oraz propozycje zmian traktowane są często raczej jako przejaw roszczeniowej postawy młodego pokolenia, niż działania, które można wykorzystać dla rozwoju pozytywnych postaw i przekonań studentów.

\section{Obserwowanie zachowania innych}

Trzecim, zdaniem A. Bandury, oprócz perswazji słownej i doświadczania własnych sukcesów, źródłem informacji budującym przekonanie, iż można 
odnosić sukcesy w jakimś działaniu jest obserwowanie sukcesów odnoszonych w tym działaniu przez innych ludzi.

W murach każdego polskiego uniwersytetu pracują uczeni światowego formatu, a sukces w nauce rzadko przychodzi bez własnej aktywności i samodzielnego kształtowania środowiska pracy, samodzielność jest przecież jedną z akademickich wartości ${ }^{26}$. Uczeni muszą samodzielnie troszczyć się o swoje granty, badania, publikacje oraz o prowadzone zajęcia, jeśli jeszcze osiągają przy tym poziom mistrzowski, to są osobowościami wybitnymi. Spotkania z wybitnymi naukowcami i poznanie historii ich rozwoju zawodowego mogłyby być niecodzienną, inspirującą lekcją uzmysławiającą studentom potrzebę samodzielności i własnej aktywności w działaniach zawodowych. Zatem, trzecim sposobem kształtowania w studentach przekonania, że warto i należy aktywnie zmieniać swoje zawodowe środowisko, mogłoby być obserwowanie, jak swój sukces odnieśli wybitni naukowcy. $\mathrm{W}$ toku edukacji uniwersyteckiej, studenci mogliby uczestniczyć w specjalnych kursach - spotkaniach z wybitnymi naukowcami, w ramach których nacisk byłby położony nie tyle na merytoryczny aspekt sukcesów naukowych profesorów, co na kontekst osiągania tych sukcesów. Studenci obserwując, jak wiele własnej aktywności i zmagania się z przeciwnościami konieczne jest do odniesienia sukcesu w nauce, mogliby wyciągać wnioski co do własnych przyszłych poczynań zawodowych. Możliwość osobistego spotkania z naukowcami odnoszącymi sukcesy w swojej dziedzinie, poznanie ich problemów oraz sposobów, $\mathrm{w}$ jaki się z nimi zmagają, może wzmacniać w studentach przekonanie o konieczności aktywnego kształtowania otaczającego środowiska zawodowego, a przez to przyczynić się do rozwoju zaangażowania w przyszłej pracy.

\section{Podsumowanie}

Celem artykułu jest przedstawienie idei, iż uniwersytety mogą kształcić ludzi zaangażowanych $\mathrm{w}$ pracę poprzez budowanie $\mathrm{w}$ studentach przekonania o własnej skuteczności $\mathrm{i}^{27} \mathrm{~W}$ zakresie aktywnego zmieniania środowiska pracy $^{28}$. Graficzną ilustrację prezentowanej idei przedstawia rycina 1. Podsumowując, wydaje się, iż uniwersytety mogłyby kształcić ludzi zaangażowa-

${ }^{26}$ Akademicki Kodeks Wartości UJ, 2003 http://www.uj.edu.pl/c/document_library/ get_file?uuid=d63b4be0-5eee-4d94-bd32-3b1ccef396f6\&groupId=10172 [dostęp: 26.11.2016].

27 A. Bandura, Self-efficacy: toward a unifying theory, s. 191-215; tenże, Teoria społecznego uczenia się.

${ }_{28}$ A.B. Bakker, M. Tims, D. Derks, Proactive personality and job performance: The role of job crafting and work engagement, Human Relations, 2012, 65, s. 1359-1378. 
nych w swoją przyszłą pracę poprzez rozwijanie w studentach przekonania o potrzebie aktywnego kształtowania środowiska pracy. Takie przekonanie można by kształtować na trzy sposoby, poprzez: (1) specjalnie zaprojektowane zajęcia - treningi własnej aktywności w środowisku zawodowym; (2) umożliwienie studentom odnoszenia sukcesów w aktywnościach ukierunkowanych na zmienianie rzeczywistości uniwersyteckiej oraz (3) umożliwienie studentom obserwowania aktywności wybitnych uniwersyteckich naukowców, którzy dzięki swym działaniom odnieśli sukces.

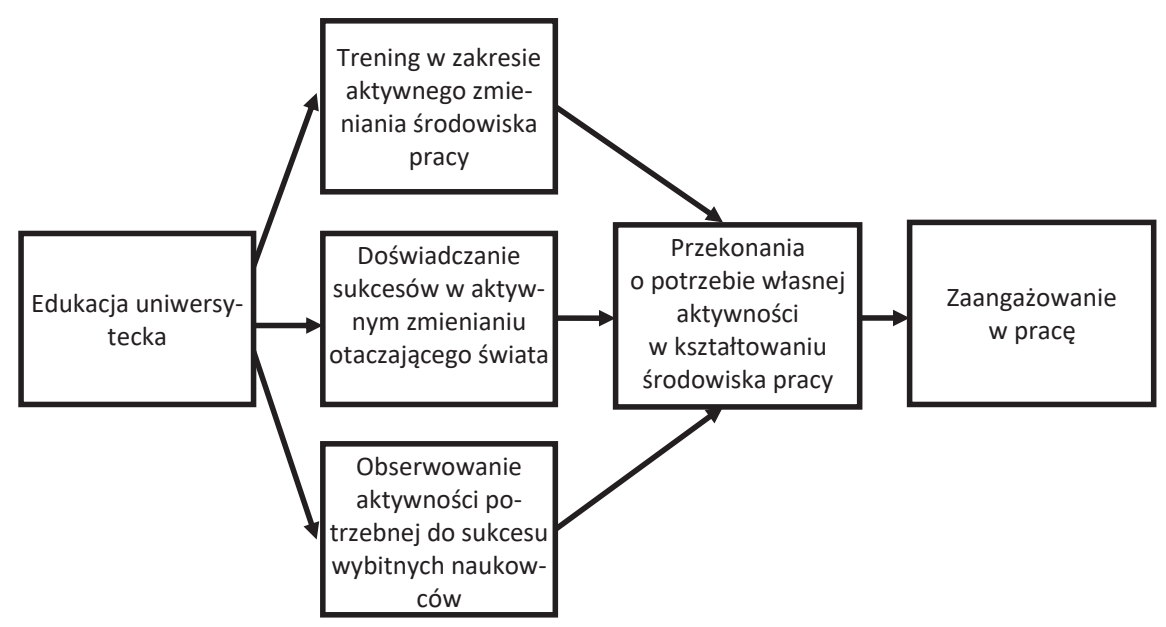

Ryc. 1. Model oddziaływania edukacji uniwersyteckiej na zaangażowanie w pracę

Proponowana idea bazuje na założeniach teoretycznych i doniesieniach empirycznych, wymaga jednak weryfikacji empirycznej. Przedstawiony pomysł można traktować jako próbę nakreślenia pewnego ideału i zarazem pierwszy krok na drodze do jego osiągnięcia. Kolejnym krokiem mogłoby być wdrożenie pilotażowego programu monitorującego, czy postulowane działania $\mathrm{w}$ praktyce przynoszą oczekiwane rezultaty $\mathrm{w}$ postaci zwiększenia aktywności i zaangażowania przyszłych pracowników. Wydaje się, iż warto podjąć działania, które przyczyniłyby się do tego, że absolwenci uniwersytetów będą nie tylko świetnymi fachowcami wyposażonymi w aktualną wiedzę, ale także aktywnymi i zaangażowanymi pracownikami. Tego, jak pracować z zaangażowaniem nie uczy żadna szkoła, studium ani akademia. Niestety, nie uczą tego także uniwersytety - a być może mogłyby. 


\section{BIBLIOGRAFIA}

Airila A., Hakanen J.J., Schaufeli W.B., Luukkonen R., Punakallio A., Lusa S., Are job and personal resources associated with work ability 10 years later? The mediating role of work engagement, Work \& Stress, 2014, 28(1).

Akademicki Kodeks Wartości UJ (2003), http://www.uj.edu.pl/c/document_library/get_ file?uuid=d63b4be0-5eee-4d94-bd32-3b1ccef396f6\&groupId=10172 [dostęp: 27.11.2016].

Artino A.R., Academic self-efficacy: from educational theory to instructional practice, Perspectives on Medical Education, 2012, 1.

Bakker A.B., Bal M.P., Weekly Work Engagement and Performance: A Study among Starting Teachers, Journal of Occupational and Organizational Psychology, 2010, 83(1).

Bakker A.B., Albrecht S.L., Leiter M.P., Work engagement: Further reflections on the state of play, European Journal of Work and Organizational Psychology, 2011, 20(1).

Bakker A.B., Tims M., Derks D., Proactive personality and job performance: The role of job crafting and work engagement, Human Relations, 2012, 65.

Bakker A.B., Sanz-Vergel A.I., Weekly work engagement and flourishing: The role of hindrance and challenge job demands, Journal of Vocational Behavior, 2013, 83(3).

Bakker A.B., Demerouti E., The Job Demands-Resources Theory, [w:] Work and Wellbeing: A Complete Reference Guide, Vol. III, red. P.Y. Chen, C.L. Cooper, John Wiley \& Sons, West Sussex 2014.

Bandura A., Self-efficacy: toward a unifying theory of behavioral change, Psychology Review, $1977,84$.

Bandura A., Teoria społecznego uczenia się, Wydawnictwo Naukowe PWN, Warszawa 2007.

Demerouti E., Design your own job through job crafting, European Psychologist, 2014, 19(4).

Demerouti E., van Eeuwijk E., Snelder M., Wild U., Assessing the effects of a 'personal effectiveness' training on psychological capital, assertiveness and self-awareness using self other agreement, Career Development International, 2011, 16.

Demerouti E., Bakker A., Job Crafting, [w:] An Introduction to Contemporary Work Psychology, red. M.C.W. Peeters, J. de Jonge, T.W. Taris, John Wiley \& Sons, West Sussex 2014.

Grant A.M., Parker S.K., Redesigning work design theories: The rise of relational and proactive perspectives, Academy of Management Annals, 2009, 3.

Hakanen J.J., Schaufeli W.B., Do burnout and work engagement predict depressive symptoms and life satisfaction? A three-wave seven-year prospective study, Journal of Affective Disorders, 2012, 141(2-3).

Harrison W., Rainer R.K., Hochwarter W., Thompson K.R., Testing the self-efficacy-performance linkage of social-cognitive theory, The Journal of Social Psychology, 1997, 137.

Harter J.K., Schmidt F.L., Asplund J.W., Killham E.A., Agrawal S., Causal Impact of Employee Work Perceptions on the Bottom Line of Organizations, Perspectives on Psychological Science, 2010, 5(4).

Kahn W.A., Psychological condition of Personal Engagement and Disengagement at Work, Academy of Management Journal, 1990, 33(4).

Kahn W.A., To Be Fully There: Psychological Presence at Work, Human Relations, 1992, 45(4).

Karatepe O.M., Beirami E., Bouzari M., Safavi H.P., Does work engagement mediate the effects of challenge stressors on job outcomes? Evidence from the hotel industry, International Journal of Hospitality Management, 2014, 36.

Lu C., Wang H., Lu J., Du D., Bakker A.B., Does work engagement increase person-job fit? The role of job crafting and job insecurity, Journal of Vocational Behavior, 2014, 84(2).

Macey W.H., Schneider B., The Meaning of Employee Engagement, Industrial and Organizational Psychology, 2008, 1(1). 
Maslach C., Leiter M.P., Early Predictors of Job Burnout and Engagement, Journal of Applied Psychology, 2008, 93(3).

Parker S.K., Wall T.D., Cordery J., Future work design research and practice: Towards an elaborated model of work design, Journal of Occupational and Organizational Psychology, 2001, 74 .

Petrou P., Demerouti E., Peeters M.C.W., Schaufeli W.B., Hetland J., Crafting a job on a daily basis: contextual antecedents and the effect of work engagement, Journal of Organizational Behavior, 2012, 33.

Sakuraya A., Shimazu A., Imamura K., Namba K., Kawakami N., Effects of a job crafting intervention program on work engagement among Japanese employees: a pretest-posttest study, BMC Psychology, 2016, 4(1) http:/ / doi.org/10.1186/s40359-016-0157-9.

Schaufeli W.B., Salanova M., González-Roma V., Bakker A.B., The measurement of engagement and burnout: a two sample confirmatory factor analytic approach, Journal of Happiness Studies, 2002, 3(1).

Schaufeli W.B., Bakker A.B., Salanova M., The measurement of work engagement with a short questionnaire: A cross-national study, Educational and Psychological Measurement, 2006, 66.

Schaufeli W.B., Taris T.W., van Rhenen W., Workaholism, Burnout, and Work Engagement: Three of a Kind or Three Different Kinds of Employee Well-being? Applied Psychology, 2008, 57(2).

Schaufeli W.B., Bakker A.B., Defining and measuring work engagement: Bringing clarity to the concept, [w:] Work engagement: a handbook of essential theory and research, red. A.B. Bakker, M.P. Leiter, Psychology Press, New York 2010.

Sheldon K.M., King L., Why positive psychology is necessary, American Psychologist, 2001, 56(3).

Shimazu A., Schaufeli W.B., Kamiyama K., Kawakami N., Workaholism vs. Work Engagement: the Two Different Predictors of Future Well-being and Performance, International Journal of Behavioral Medicine, 2015, 22(1).

Tims M., Bakker A.B., Derks D., Development and validation of the job crafting scale, Journal of Vocational Behavior, 2012, 80(1).

Tims M., Bakker A.B., Derks D., The Impact of Job Crafting on Job Demands, Job Resources, and Well-Being, Journal of Occupational Health Psychology, 2013, 18(2).

UJ (2015) Studia w języku polskim nabór na rok 2015/2016, Online: <https://www.erk. uj.edu.pl/studia/katalog/rok_rekrutacji/15/tryb_ubiegania/s/widocznosc/t>. [dostęp: 16.10.2015].

Wrzesniewski A., Dutton J.E., Crafting a job: Revisioning employees as active crafters of their work, Academy of Management Review, 2001, 26.

Xanthopoulou D., Bakker A.B., Demerouti E., Schaufeli W.B., Work engagement and financial returns: A diary study on the role of job and personal resources, Journal of Occupational and Organizational Psychology, 2009,82(1). 